The site-territory hypothesis gives a simple explanation for the segregation of two daughter chromosomes. New sites would be formed as far away as possible from the existing site and from each other. If cell division is triggered at the existing site ${ }^{7}$, the daughter chromosomes would be found segregated in the daughter cells. The model makes no predictions about more complicated problems of segregation $2,5,7$.

Direct control of DNA replication by membrane structure would be relevant to discussion of contact inhibition.

The site-territory hypothesis differs slightly from previous models ${ }^{1-3}$. It predicts that existing sites control initiation of DNA replication by repressing the formation of new sites until sufficient new membrane is made. The model is presented with the hope that it may stimulate the design of new types of experiments.

This work was supported in part by a grant from the US Public Health Service.

Department of Molecular Biophysies,

D. A. Marvin

Yale University,

New Haven, Connecticut.

Received June 4, 1968.

1 Jacob, F., Brenner, 8., and Cuzin, F., Cold Spring Harbor Symp. Quant. Biol., 28, 329 (1963),

s Lark, K. G., Bact. Rev., 30, 3 (1966).

'Maaløe, O., and Kjeldgaard, N. O., Control of Macromolecular Synthesis (Benjamin, New York and Amsterdam, 1966).

${ }^{4}$ Ganesan, A. T., in Organizational Biosynthesis (edit. by Vogel, H. J. Lampen, J. o.., and Bryson, v.), 19 (Academic Press, New York and London, 1967).

${ }^{5}$ Lark, K. G., Eberle, H., Consigli, R. A., Minocha, H. C., Chai, N., and Lark, and Bryson, V.), 03 (Academic Press, New York and London, 1967).

- Sueoka, N., in Molecular Genetics: Part II (edit. by Taylor, J. H.), 1 (Academic Press, New York and London, 1967).

' Ryter, A., Bact. Rev., 32, 39 (1968).

${ }^{3}$ Denhardt, D. T., and Sinsheimer, R. L., J. Mol. Biol., 12, 641 (1965).

${ }^{9}$ Yarus, M. J., and Sinsheimer, R. L., J. Virol., 1, 135 (1967).

${ }^{10}$ Stone, A. B., Biochem. Biophys. Res. Commun., 26, 247 (1967).

${ }^{11}$ Sinsheimer, R. L., Hutchison, C. A., and Lindqvist, B. H., in The Molecular Biology of Viruses (edit. by Colter, J. S., and Paranchych, W.), 175 (Academic Press, New York and London, 1967).

${ }^{18}$ Sinsheimer, R. L., in The Molecular Biology of Viruses (edit. by Crawford, L. V., and Stoker, M. G. P.), 101 (Cambrídge Univ, Press, 1968).

${ }^{13}$ Levine, A. J., and Sinsheimer, R. L., J. Mol. Biol., 32, 567 (1968). ${ }^{14}$ Changeux, J.-P.. Thiery, J., Tung, X., and Kittel, C., Proc. US Nat. Acad.
Sci., 57,' 335 (1967).

${ }^{15}$ Hill, T. L., Proc. US Nat. Acad. Sci., 58,'111 (1967).

${ }_{16}$ Nomura, M., Ann. Rev. Microbiol., 21, 257 (1967).

${ }^{17}$ Changeux, J.-P., and Thiéry, J., J. Theoret. Biol., 17, 315 (1967).

${ }^{18}$ Harris, R. A., Penniston, J. T., Asai, J., and Green, D. E., Proc. US Nat. Acad. Sci., 59,830 (1968).

${ }^{19}$ Maaløe, O., in Phage and the Origins of Molecular Biology (edit. by Cairns, J., Stent, G. S., and Watson, J. D.), 265 (Cold Spring Harbor Laboratory of Quantitative Biology, 1966).

${ }^{20} \mathrm{Clark}$, D. J., and Maaløe, O., J. Mol. Biol., 23, 99 (1967).

${ }^{21}$ Helmstetter, C. E, and Cooper, S., J. Mol. Biol. 31, 507 (1968).

${ }^{22}$ Cooper, S., and Helmstetter, C. E., J. Mol. Biol., 31, 519 (1968).

\section{AMP on an Insoluble Solid Support}

WHILE investigating some fundamental interactions of amino-acids with nucleotides, we became interested in the possibility of attaching adenosine $5^{\prime}$-monophosphate (AMP) to an insoluble support. If AMP could be bound to a polymer frame by means of the phosphate function, the result would be a reactive site (template) which bears some resemblance to the amino-acid acceptor terminus of a transfer (soluble) ribonucleic acid $(t \mathrm{RNA})^{1}$. The similarity is represented schematically in Fig. 1.

The availability of Merrifield's chloromethylated polystyrene resin ${ }^{2}$ (commercially available as 'Bio-Beads $S X \cdot 2$ ', Bio-Rad Laboratories, Richmond, California) suggested an attempt to apply the general scheme utilized in the field of peptide synthesis on a solid support (that is, the formation of a "benzyl" ester between the polymer and the acidic function). Subsequent experiments established that AMP could be attached to the rosin by a bond which could be cleaved in non-destructive conditions, as shown in Fig. 2. The stability of the bond in neutral and

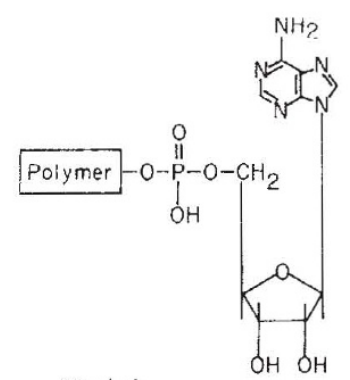

Model

Template

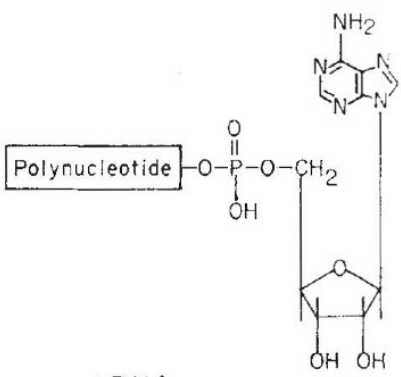

tRNA

Terminus
Fig. 1.

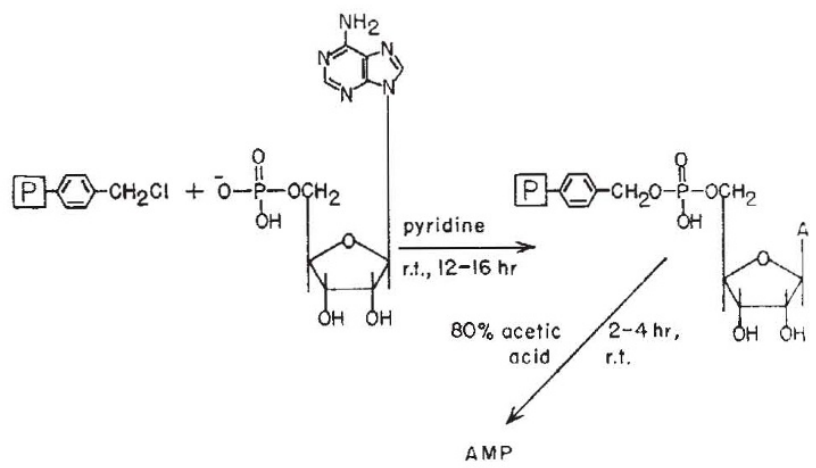

Fig. 2. AMP was bound to polystyrene as follows. Coupling: $10 \mathrm{~g}$ of resin (0.72 mequiv. of $\mathrm{Cl} / \mathrm{g})$ was mixed with $2 \mathrm{mM}$ AMP and $100 \mathrm{ml}$. of pyridine, and washed with water, dioxane and finally methanol. $\mathrm{g}$ of coupled and washed product was mix
of 80 per cent aqueous glacial acetic acid.

mildly basic conditions, coupled with its facile rupture when treated with aqueous acetic acid, argues for its covalent nature and is consistent with the representation of a "benzyl" phosphodiester species. The use of AMP $\left(8 .{ }^{14} \mathrm{C}\right)$ in this scheme made possible an analysis of the liberated material by a combination of paper chromatography and spectroscopic methods as outlined in Fig. 3. Several independent determinations of the bound nucleotide disclosed an avorage of $115( \pm 5) \mu$ moles of AMP $/ g$ of polymer.

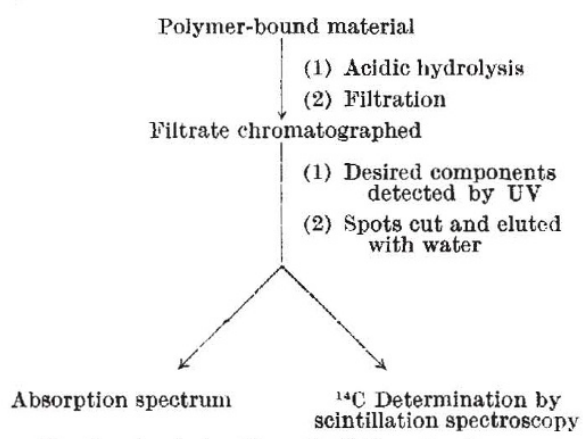

Fig. 3. Analysis of bound AMP and polymer.

This work was supported by the US Atomic Energy Commission and the US National Institutes of Health, General Medical Sciences Division.

$$
\text { Michael A. Harpold }
$$$$
\text { Melvin Calvin }
$$

Department of Chemistry and

Laboratory of Chemical Biodynamies,

Lawrence Radiation Laboratory,

University of California,

Berkeley.

Received May 30, 1968.

1 Mahler, H. R., and Cordes, E. H., Biological Chemistry, 796 (Hitrjer and Row, New York, 1966)

' Merrifleld, R. B., J. Amer. Chem. Soc., 85, 2149 (1963). 